\title{
Mammal Notes
}

\section{Coyote Tolling a Calf}

By Robert W. Nero, Saskatchewan Museum of Natumal History

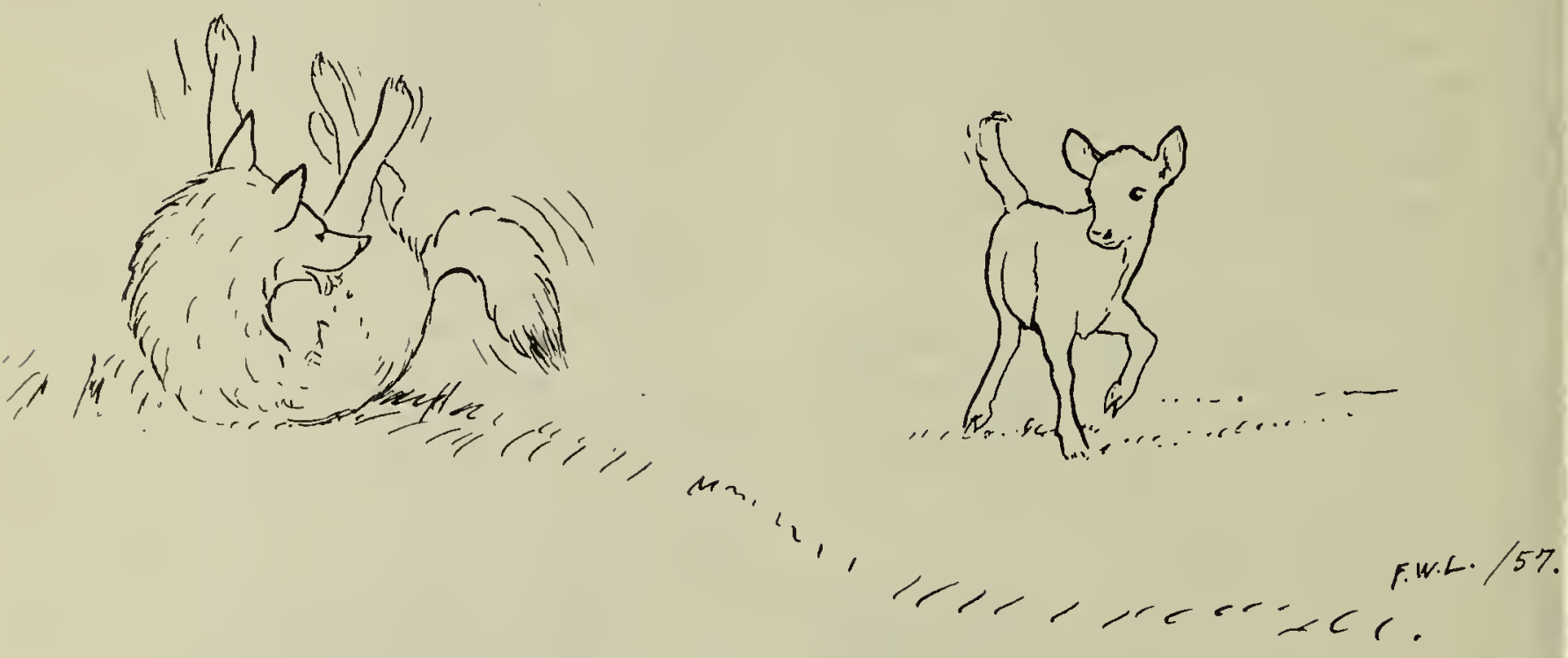

Sketch by F. W. Lahrmar

Students of animal behavior are not always able to observe a species long enough to see all of its behavior, particularcly where large mammals are concerned. Chance observation's by farmers, ranchers and others closely associated with wildlife species are thus valuable and sometimes unique, but are seldom recarded. When observations can be permanently recorded and made available to others they assume a greater value. The following observations of a Coyote (Canis latrans) attempting to catch a calf by luring it away from a herd were made by Mr. A. E. Swanston (Museum Assistant-S.M.N.H.) and Mr. T. Walker (former Museum Assistant) on June 29, 1952. This unique situation was related to me by Mr. Swanston who referred to notes in his field diary made at the time. It has been confirmed by $\mathrm{Mr}$. Walker.

Both persons were on a museum field camp at Stewart's Ranch, 14 miles northwest of Eastend, Saskatchewan. In the evening, between 7:30 and 8:00 p.m. and shortly before darkness fell, they had gone out to check a hawk's nest and were ambling along the bottom of a valley when they noticed a Coyote on a high bench. Almost at once they realized that the Coyote was behaving in an unusual manner: it turned around in circles, rolled over like a dog and then stood up and looked down on a herd of beef cattle which were grazing below. All this time the Coyote was in full sight of the herd Sometimes the Coyote walked around slowly but it remained in one smal. area all the while it was "stunting.' Meanwhile, the two observers, evidently unnoticed by the Coyote, became aware that a small calf hac come out from the herd and wa: advancing toward the Coyote at about 150 yards distance. The cal was then some 50 to 75 yards from the herd and kept advancing slowly while looking up at the Coyote. The latter kept up his "playful" behav. ior for perhaps 15 minutes until the calf was 50 to 75 yards away. Ther the Coyote suddenly and withou any warning dashed down the slope of the bench toward the calf. The calf turned and fled bellowing to ward the herd as soon as the Coyot started his run. The cattle all begar to run toward the calf and in a feu minutes the calf was safe. Th Coyote had come within possibly 31 feet of the calf and both observer agreed that if the herd had not ru toward the calf the latter might hav been caught by the Coyote. Whel the calf was close to the herd thi Coyote had veered off and slowl: run along the outer edge of the herd not evidently frightened; it finall. disappeared on the other side of th coulee.

The hunting behavior of the Coyot (and other Canidae) has long at tracted attention. Every schoolboy 
for example, has heard of Coyotes hunting in pairs, one animal driving the game toward another Coyote lying in wait. The deliberate attempt to hold attention of prey or to lure it within range as described above is especially interesting in view of its indirectness. Coyotes have several times been recorded working in pairs, one attracting the attention of the prey by performing antics like those reported above, while another sneaks up unnoticed. J. F. Dobie (1949. The Voice of the Coyote) cites good examples of this: ". . . noticed a coyote silently jumping up and around. Then he saw a second coyote off some distance slinking slowly and carefully forward. Between the two a sitting jack rabbit appeared to be fascinated by the didos of the first coyote and to be unaware of the approach of the other..." In another case he recounts how coyotes caught some pelicans, one coyote attracting their attention by catching up bits of wood and throwing them into the air, chasing her tail, crouching and making sudden springs into the air." Even a Sandhill Crane was caught in this way by another couple of coyotes, one of which was turning somersaults and running round and round. This behavior of a wild species has close similarity to an old method of luring ducks called "tolling" and much favoured in Europe. The same method is being used at present with great success at the Delta Waterfowl Research Station (Delta, Manitoba). A well-trained dog is directed by his concealed trainer to go through a complicated series of maneuvers, performing play-like movements in full sight of a flock of wild ducks. The latter are strangely attracted by the antics of the dog and are thereby lured into a trap. Thousands of ducks have been trapped and banded at Delta by this means.

\section{Gray Squirrel (Sciurus carolinensis) in Sask.}

By Robert W. Nero, Saskatchewan Museum of Natural History

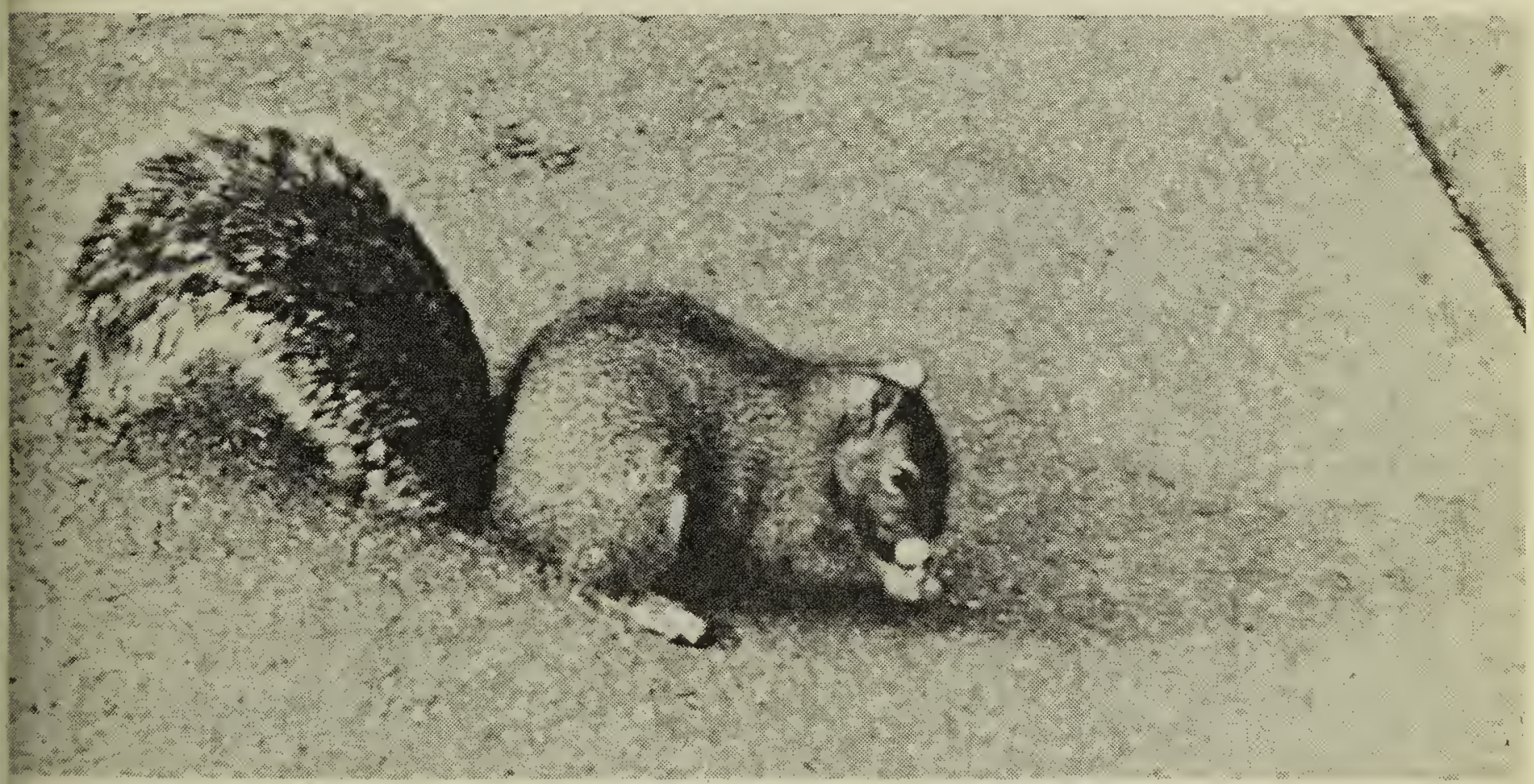

Photo trom a kodachrome by Iohn Bergsteinsson

Gray Squirrel feeding on a Saskatoon sidewalk.

The occurrence of the Gray Squirrel (Sciurus carolinensis) some 70 miles north of Regina is unexpected considering its known range and habits, and it seeems likely that it has been introduced into this area." It is known to occur normally in southeastern Manitoba west to Ninette according to R. W. Sutton (pers. commun.) but it is rare and only locally distributed in this area. In the United States it is found as far west as eastern North Dakota. There are a $1 \mathrm{so}$ isolated occurrences in north-central North Dakota along the bottom of the loop of the Souris River (Mouse River in the U.S.) which probably represent introductions (Hibbard, 1956). The follow- 